\title{
Non-endocrine disruptor effect for cardanol based plasticizer
}

\author{
Benoit Briou $^{1}$, Sylvain Caillol ${ }^{1}$, Jean-Jacques Robin ${ }^{1}$, Vincent Lapinte $^{1 *}$
}

1: Institut Charles Gerhardt Montpellier UMR-5253, CNRS, UM, ENSCM, Equipe Ingénierie et Architectures Macromoléculaires, Université Montpellier cc1702, Place Eugène Bataillon 34095 Montpellier Cedex 5, France.

\section{Abstract}

A series of bio-based epoxidized plasticizers (CExEp) for soft PVC was synthesized from cardanol and various fatty acids by esterification and epoxidation of the fatty and cardanol unsaturations. The plasticizing properties of these additives for PVC films were proved considering thermal and mechanical data. They seem to be a good bio-based alternative plasticizer to diisononyl phthalate (DINP), one of the most widespread phthalate plasticizers, with more flexible and stable films. Non epoxidized plasticizers (CEx) give satisfying results as secondary plasticizers of DINP whereas epoxidized ones act as primary plasticizers. The synergy between epoxy groups and cardanol ring to elaborate efficient primary plasticizers was demonstrated. Moreover, the eco-toxicity using daphnies, algae, and plants as model organisms and endocrinal disruptor tests (YES/YAS) were realized on the best candidate. Our results revealed that the fatty cardanol plasticizer causes a global decrease in toxicity compared to DINP and no harm for environment and human health were detected without reprotoxicity effect. 


\section{Introduction}

Poly(vinyl chloride) (PVC) is one of the most used polymers in the world due to its high versatility, its accommodation with many additives, its good mechanical properties and its low cost production. It is expected that PVC annual production reaches 59 million tons in 2020 [1-3]. The applications extend from highly rigid PVC (window profiles, computer housings, outdoor products, containers, blister packages) to flexible PVC using some additives like plasticizers with a mass ratio ranging from 30 to 50\%. Soft PVC formulations can be employed in the medical field, for packaging materials, artificial leather and toys... [47] In the last decade, the worldwide production of plasticizers has been about 5 million tons per year. More than $80 \%$ of these additives are phthalates bearing long alkyl chains like diisononyl phthalate (DINP) or bis(2-ethylhexyl)phthalate (DEHP). Thanks to their low cost and good performances with PVC, these additives are produced in large quantities. However, reprotoxicity of phthalates on both animals and humans is reported [8-14] and some of them were recently banned by European regulation 2000/60/CE and European Regulation 1907/2006/CE regulations. Moreover, the development of polymers from renewable resources is of paramount importance in a sustainable development approach. In this context, the current trend shifts toward non-toxic and renewable plasticizers. $[15,16]$ Numerous bio-based plasticizers have already been investigated including epoxidized sunflower oil, epoxidized safflower oil, low-molecular-weight glycerol esters or cardanol based plasticizers. [17-19] Cardanol, obtained by vacuum distillation of cashew nut shell liquid (CNSL), is a promising non-edible and non-toxic renewable resource. CNSL is directly extracted from the shell of the cashew nut, fruit from cashew tree, Anacardium occidentale. This tree is mainly grown in India and also in East Africa and Brazil and the total production of cardanol approaches an annual output of around 500,000 tons. [20] Cardanol is constituted of a mixture of at least four constituents differing in the unsaturated side chain, namely saturated (5-8\%), monoene 
(48-49\%), diene (16-17\%) and triene (29-30\%) as illustrated in Figure 1. Its phenolic group can be functionalized by etherification, esterification... whereas various additions can be performed on the double bond of the alkyl side chain. Cardanol and its derivatives found a lot of applications in the field of material [20] as additives (antioxidants [21], surfactants or plasticizers) or as building blocks for polymers [22], (epoxy curing agents [23]), coatings [24] and composites. [25-28] In the last ten years, many studies have been focused on the synthesis of cardanol-based PVC plasticizers. Indeed, due to its aromatic groups bringing thermal stability and its C15 alkyl chain that could confer a plasticizing effect, cardanol can be considered as a promising substituent to phthalates. Esterified cardanols by short alkyl chains have already shown good results as secondary plasticizers in presence of DEHP. [19, 29] Epoxidation of double bonds improves the plasticizing properties and the thermal stability of PVC as previously demonstrated on esterified cardanol bearing short alkyl chain (i.e. acetate) and used as an efficient primary plasticizer. [30] Knowing the efficiency of plasticizers bearing long alkyl chains, the modification of epoxidized cardanol by various fatty acids seems relevant.

Herein, we report the two-step synthesis of a series of fully bio-based plasticizers from epoxidized and esterified cardanol using fatty esters. The influence of the epoxidation of the cardanol and fatty chains on the plasticizing properties was performed from mechanical and thermal studies. These plasticizers were also compared to DINP, one of the most widespread phthalate plasticizers. Finally, the eco-toxicity and endocrinal disruptor tests were performed on the best candidate to phthalate substitution on PVC formulations. 


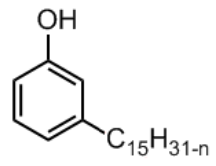

Cardanol

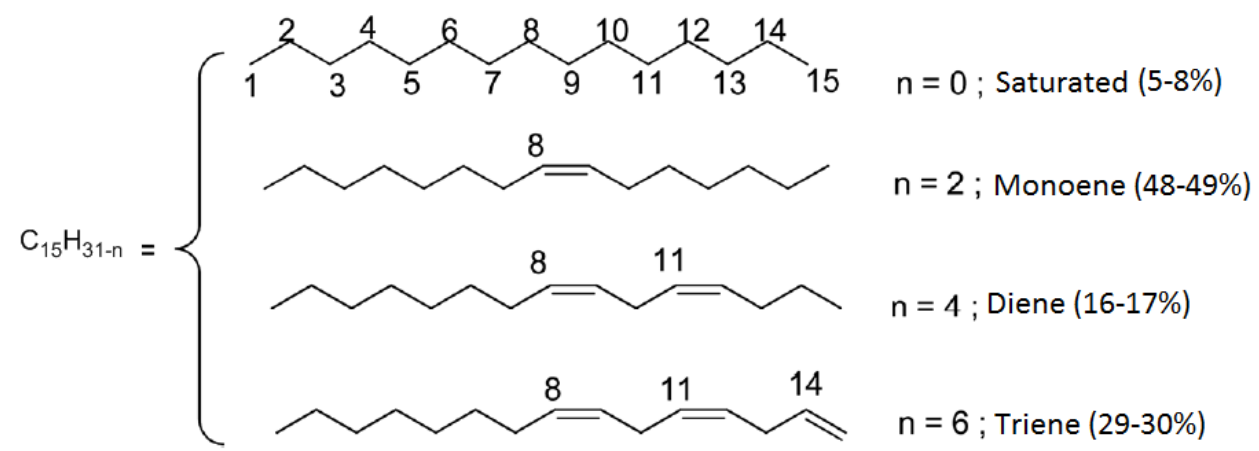

Figure 1. The global chemical structure of cardanol with its various fatty chains 


\section{Experimental}

\section{Materials}

Cardanol (NX 2026) was provided by Cardolite. PVC P70 was purchased from Vinnolit in powder form. DINP, myristic acid, acetic acid, oleic acid, 4-dimethylaminopyridine (DMAP), sulfuric acid $\left(\mathrm{H}_{2} \mathrm{SO}_{4}\right)$ Silica and hydrogen peroxide were purchased from Sigma-Aldrich.1Ethyl-3-(3-dimethylaminopropyl) carbodiimide was purchased from TCI and, cyclohexane and ethyl acetate were purchased from analytic lab.

\section{Synthesis of cardanol-esters (CEx)}

Several acids (acetic acid, myrisitic acid and oleic acid) were used according the same procedure. To a mixture of cardanol $(49.83 \mathrm{mmol}, 1 \mathrm{eq})$, acid $(49.83 \mathrm{mmol}, 1 \mathrm{eq})$ and DMAP (24.91 mmol, 0.5 eq), EDC (99.66 mmol, 2eq) was added. The mixture was stirred at room temperature for four hours. The reaction was monitored by Thin Layer Chromatography. After the completion of the reaction, the solvent was removed by vacuum evaporation. The residue was dissolved in ethyl acetate and washed three times with water. The crude product was purified by chromatography on a silica column (cyclohexane/ethyl acetate 95:5).

CE2: Isolated yield 64\%, liquid, ${ }^{1} \mathrm{H}$ NMR $\left(\mathrm{CDCl}_{3}\right), \delta(\mathrm{ppm})$ 0.82-0.91 (m, $\left(\mathrm{CH}_{3}\right), 1.2-1.35$ (m, $\left.\mathrm{CH}_{2}\right)$, 1.52-1.64 (m, $\left.\mathrm{CH}_{2}\right)$, 1.93-2.05 (m, $\left.\mathrm{CH}_{2}\right), 2.30\left(\mathrm{~s}, \mathrm{CH}_{3}\right)$, 2.53-2.60 (t, $\left.\mathrm{CH}_{2}\right), 2.71-$ $2.82\left(\mathrm{~m}, \mathrm{CH}_{2}\right), 4.92-5.06\left(\mathrm{~m}, \mathrm{CH}_{2}=\right), 5.24-5.42(\mathrm{~m}, \mathrm{CH})$, 5.71-5.86 (m, $\left.\mathrm{CH}\right), 6.84-6.88(\mathrm{~m}$, aromatic $\mathrm{CH})$, 6.98-7.03 (d, aromatic $\mathrm{CH}), 7.20-7.23(\mathrm{dd}$, aromatic $\mathrm{CH})$ ).

CE14: Isolated yield 66\%, liquid, ${ }^{1} \mathrm{H} \mathrm{NMR}\left(\mathrm{CDCl}_{3}\right), \delta(\mathrm{ppm})$ 0.86-0.91 (m, $\left(2 \mathrm{CH}_{3}\right), 1.27$ $1.31\left(\mathrm{~m}, \mathrm{CH}_{2}\right), 1.53-1.67\left(\mathrm{~m}, \mathrm{CH}_{2}\right), 1.69-1.80\left(\mathrm{t}, \mathrm{CH}_{2}\right), 1.97-2.09\left(\mathrm{~m}, \mathrm{CH}_{2}\right), 2.50-2.57$ (t, 
$\left.\mathrm{CH}_{2}\right)$ 2.57-2.63 (t, $\left.\mathrm{CH}_{2}\right), 2.76-2.86\left(\mathrm{~m}, \mathrm{CH}_{2}\right), 4.95-5.09\left(\mathrm{~m}, \mathrm{CH}_{2}=\right)$, 5.30-5.46 (m, $\left.\mathrm{CH}\right)$, 5.75$5.88(\mathrm{~m}, \mathrm{CH})$, 6.85-6.91 (m, aromatic $\mathrm{CH})$, 7.00-7.05 (d, aromatic $\mathrm{CH}), 7.22-7.27$ (dd, aromatic $\mathrm{CH})) .{ }^{13} \mathrm{C} \mathrm{NMR}\left(\mathrm{CDCl}_{3}\right), \delta(\mathrm{ppm}) 14.2\left(\mathrm{CH}_{3}\right), 22.8\left(\mathrm{CH}_{2}\right), 25\left(\mathrm{CH}_{2}\right), 25.6\left(\mathrm{CH}_{2}\right)$, $27\left(\mathrm{CH}_{2}\right), 27.3\left(\mathrm{CH}_{2}\right), 29.3-29.7\left(\mathrm{CH}_{2}\right), 31.3\left(\mathrm{CH}_{2}\right), 32\left(\mathrm{CH}_{2}\right), 34.5\left(\mathrm{CH}_{2}\right), 35.8\left(\mathrm{CH}_{2}\right), 114.8$ $\left(\mathrm{CH}_{2}=\right), 118.8(\operatorname{aromatic} \mathrm{CH}), 121.5(\operatorname{aromatic} \mathrm{CH}), 125$ (aromatic $\left.\mathrm{CH}\right), 129(\operatorname{aromatic} \mathrm{CH})$, 126-136.9 ( $\mathrm{CH}$ of side alkyl chain), 144.7 (C-alkyl chain), 150.9 (C-O), 172.4 (O-C=O ester).

CE18:1: Isolated yield 86\%, liquid, ${ }^{1} \mathrm{H}$ NMR $\left(\mathrm{CDCl}_{3}\right), \delta(\mathrm{ppm})$ 0.81-0.91 (m, $\left(2 \mathrm{CH}_{3}\right), 1.2-$ $1.36\left(\mathrm{~m}, \mathrm{CH}_{2}\right), 1.53-1.62\left(\mathrm{~m}, \mathrm{CH}_{2}\right), 1.64-1.75\left(\mathrm{t}, \mathrm{CH}_{2}\right), 1.93-2.07\left(\mathrm{~m}, \mathrm{CH}_{2}\right), 2.45-2.53(\mathrm{t}$, $\left.\mathrm{CH}_{2}\right)$ 2.53-2.61 (t, $\left.\mathrm{CH}_{2}\right), 2.71-2.82\left(\mathrm{~m}, \mathrm{CH}_{2}\right), 4.90-5.05\left(\mathrm{~m}, \mathrm{CH}_{2}=\right), 5.24-5.42(\mathrm{~m}, \mathrm{CH}), 5.72-$ $5.86(\mathrm{~m}, \mathrm{CH})$, 6.80-6.87 (m, aromatic $\mathrm{CH}), 6.99-7.06(\mathrm{~d}$, aromatic $\mathrm{CH}), 7.19-7.27$ (dd, aromatic $\mathrm{CH}) .{ }^{13} \mathrm{C} \mathrm{NMR}\left(\mathrm{CDCl}_{3}\right), \delta(\mathrm{ppm}) 14.3\left(\mathrm{CH}_{3}\right), 22.8\left(\mathrm{CH}_{2}\right), 25\left(\mathrm{CH}_{2}\right), 25.8\left(\mathrm{CH}_{2}\right), 27$ $\left(\mathrm{CH}_{2}\right), 27.3\left(\mathrm{CH}_{2}\right), 29.1-29.9\left(\mathrm{CH}_{2}\right), 31.3\left(\mathrm{CH}_{2}\right), 32\left(\mathrm{CH}_{2}\right), 34.6\left(\mathrm{CH}_{2}\right), 35.9\left(\mathrm{CH}_{2}\right), 114.8$ $\left(\mathrm{CH}_{2}=\right.$ ), 118.8 (aromatic $\mathrm{CH}$ ), 121.5 (aromatic $\mathrm{CH}$ ), 126 (aromatic $\mathrm{CH}$ ), 129.2 (aromatic $\mathrm{CH}), 126.9-137(\mathrm{CH}$ of side alkyl chain), 144.7 (C-alkyl chain), 150.9 (C-O), 172.5 (O-C=O ester).

\section{Epoxidation of cardanol-ester (CExEp)}

The epoxidation was realized on different CEx (CE2, CE14, and CE181).

CEx (88.50 mmol, 1 eq), formic acid (265 mmol, 3 eq) and $\mathrm{H}_{2} \mathrm{SO}_{4}(0.885 \mathrm{mmol}, 0.01 \mathrm{eq})$ were mixed and heated at $50{ }^{\circ} \mathrm{C} . \mathrm{H}_{2} \mathrm{O}_{2}(177 \mathrm{mmol} /$ double bond, 2 eq/double bond $)$ was drop by drop added to the mixture which was stirred at $65{ }^{\circ} \mathrm{C}$ for three hours. After the completion of the reaction, water was removed from the mixture by liquid-liquid extraction. The organic phases were washed three times with water and a last dried with $\mathrm{MgSO}_{4}$. The solvent of the organic phase was removed by vacuum evaporation. 
CE2Ep: Isolate yield 96\%, liquid, ${ }^{1} \mathrm{H}$ NMR $\left(\mathrm{CDCl}_{3}\right), \delta(\mathrm{ppm})$ 0.85-0.93 (m, $\left(\mathrm{CH}_{3}\right), 1.25$ $1.40\left(\mathrm{~m}, \mathrm{CH}_{2}\right), 1.45-1.56\left(\mathrm{~m}, \mathrm{CH}_{2}\right), 1.57-1.68\left(\mathrm{~m}, \mathrm{CH}_{2}\right), 1.70-1.85\left(\mathrm{~m}, \mathrm{CH}_{2}\right), 2.28\left(\mathrm{~s}, \mathrm{CH}_{3}\right)$, 2.54-2.64 (t, CH2), 2.78-2.85 (m, $\left.\mathrm{CH}_{2}\right), 2.87-2.92\left(\mathrm{~m}, \mathrm{CH}_{2}\right), 2.93-3.01(\mathrm{~m}, \mathrm{CH}), 3.04-3.20$ (m, $\mathrm{CH}$ ), 4.97-5.96 (remnants of unsaturated bonds), 6.87-6.94 (m, aromatic $\mathrm{CH})$, 7.01-7.07 (d, aromatic $\mathrm{CH}), 7.20-7.23(\mathrm{dd}$, aromatic $\mathrm{CH})$.

CE14Ep: Isolated yield 94\%, liquid, ${ }^{1} \mathrm{H}$ NMR $\left(\mathrm{CDCl}_{3}\right), \delta(\mathrm{ppm})$ 0.84-0.93 (m, $\left(2 \mathrm{CH}_{3}\right)$, 1.22-1.31 (m, $\left.\mathrm{CH}_{2}\right), 1.32-1.39\left(\mathrm{~m}, \mathrm{CH}_{2}\right), 1.44-1.59(\mathrm{~m}, \mathrm{CH} 2), 1.56-1.65\left(\mathrm{~m}, \mathrm{CH}_{2}\right), 1.68-1.82$ (t, $\left.\mathrm{CH}_{2}\right), 2.49-2.57\left(\mathrm{t}, \mathrm{CH}_{2}\right), 2.57-2.64\left(\mathrm{t}, \mathrm{CH}_{2}\right), 2.79-2.85\left(\mathrm{~m}, \mathrm{CH}_{2}\right), 2.86-2.94\left(\mathrm{~m}, \mathrm{CH}_{2}\right)$, 2.94-3.01 (m, $\left.\mathrm{CH}_{2}\right)$, 3.04-3.20 (m, 2CH), 4.95-5.95 (remaining unsaturated bonds), 6.85$6.91(\mathrm{~m}$, aromatic $\mathrm{CH})$, 7.00-7.05 (d, aromatic $\mathrm{CH}), 7.22-7.29(\mathrm{dd}$, aromatic $\mathrm{CH}) .{ }^{13} \mathrm{C}$ NMR $\left(\mathrm{CDCl}_{3}\right), \delta(\mathrm{ppm}) 14.2\left(\mathrm{CH}_{3}\right), 22.8\left(\mathrm{CH}_{2}\right), 25\left(\mathrm{CH}_{2}\right), 26.2\left(\mathrm{CH}_{2}\right), 26.7\left(\mathrm{CH}_{2}\right), 27.2\left(\mathrm{CH}_{2}\right)$, $27.9\left(\mathrm{CH}_{2}\right), 29.2-29.9\left(\mathrm{CH}_{2}\right), 31.2\left(\mathrm{CH}_{2}\right), 32\left(\mathrm{CH}_{2}\right), 34.5\left(\mathrm{CH}_{2}\right), 35.8\left(\mathrm{CH}_{2}\right)$, 54.2-57.3 (epoxy group), 115-117.4 (remaining $\mathrm{CH}_{2}=$ ), 118.8 (aromatic $\mathrm{CH}$ ), 121.5 (aromatic $\mathrm{CH}$ ), 125.8 (aromatic $\mathrm{CH}$ ), 129.4 (aromatic $\mathrm{CH}$ ), 125.4-136.5 (remaining unsaturated bonds), 144.6 (C-alkyl chain), 150.8 (C-O), 172.4 (O-C=O ester).

CE18:1Ep: Isolated yield 96\%, liquid, ${ }_{1}^{1} \mathrm{H} \mathrm{NMR}\left(\mathrm{CDCl}_{3}\right), \delta(\mathrm{ppm})$ 0.86-0.96 (m, $\left(2 \mathrm{CH}_{3}\right)$, 1.22-1.45 (m, $\left.\mathrm{CH}_{2}\right), 1.47-1.56\left(\mathrm{~m}, \mathrm{CH}_{2}\right), 1.57-1.68\left(\mathrm{~m}, \mathrm{CH}_{2}\right), 1.70-1.82\left(\mathrm{t}, \mathrm{CH}_{2}\right), 1.97-2.10$ $\left(\mathrm{m}, \mathrm{CH}_{2}\right), 2.51-2.57\left(\mathrm{t}, \mathrm{CH}_{2}\right)$ 2.57-2.64 (t, $\left.\mathrm{CH}_{2}\right), 2.79-2.86\left(\mathrm{~m}, \mathrm{CH}_{2}\right), 2.97-2.94\left(\mathrm{~m}, \mathrm{CH}_{2}\right)$, 2.95-3.00 (m, CH), 3.03-3.18 (CH), 4.97-5.96 (remaining unsaturated bonds), 6.86-6.94 (m, aromatic $\mathrm{CH})$, 7.00-7.07 (d, aromatic $\mathrm{CH}), 7.14-7.25$ (dd, aromatic $\mathrm{CH}) .{ }^{13} \mathrm{C} \mathrm{NMR}\left(\mathrm{CDCl}_{3}\right)$, $\delta(\mathrm{ppm}) 14.2\left(\mathrm{CH}_{3}\right), 22.7\left(\mathrm{CH}_{2}\right), 25\left(\mathrm{CH}_{2}\right), 26.2\left(\mathrm{CH}_{2}\right), 26.7\left(\mathrm{CH}_{2}\right), 27,2\left(\mathrm{CH}_{2}\right), 27.9\left(\mathrm{CH}_{2}\right)$, 29.1-29.7 $\left(\mathrm{CH}_{2}\right), 31.2\left(\mathrm{CH}_{2}\right), 31.9\left(\mathrm{CH}_{2}\right), 34.5\left(\mathrm{CH}_{2}\right), 35.8\left(\mathrm{CH}_{2}\right)$, 54.3-57.3 (epoxy group), 
115-117.4 (remaining $\mathrm{CH}_{2}=$ ), 118.8 (aromatic $\mathrm{CH}$ ), 121.5 (aromatic $\mathrm{CH}$ ), 125.9 (aromatic $\mathrm{CH}$ ), 129.4 (aromatic $\mathrm{CH}$ ), 125.4-136.5 (remaining unsaturated bonds), 144.6 (C-alkyl chain), 150.8 (C-O), 172.3 (O-C=O ester).

\section{Preparation of plasticized PVC}

PVC films were formulated by mixing PVC with different plasticizers, (weight ratio 6/4) for $5 \mathrm{~min}$ at room temperature using a mechanical stirrer. The resulting plastisols were spread onto a glass surface with a $0.3 \mathrm{~mm}$ thickness and baked in an oven $10 \mathrm{~min}$ at $190{ }^{\circ} \mathrm{C}$. PVC films were cooled at room temperature during 1 hour before taking of the surface.

\section{Characterizations and measurements}

Nuclear magnetic resonance (NMR) spectra were conducted on a NMR Bruker Avance I $300 \mathrm{MHz}$ in $\mathrm{CDCl}_{3}$. The chemical shifts were in part per million (ppm), where (s) means singlet, (d) doublet, (t) triplet, (m) multiplet and (dd) doublet of doublet. For $\left({ }^{1} \mathrm{H}\right.$ NMR) chemical shifts were referenced to the peak of residual $\mathrm{CDCl}_{3}$ at $7.26 \mathrm{ppm}$. FTIR spectroscopic studies was recorded with a Perkin-Elmer Spectrum 100 spectrometer equipped with an attenuated total reflectance (ATR) cristal ( $\mathrm{ZnSe})$. The wavenumbers range was from 4000 to $650 \mathrm{~cm}^{-1}$. Dynamic mechanical analysis (DMA) were carried out in order to determine the T $\alpha$ temperature of the plasticized PVC films. These experiments were achieved using a DMA 242 E Artemis from NETZCH, under air atmosphere, from -100 to $100{ }^{\circ} \mathrm{C}$ at a heating rate of $2{ }^{\circ} \mathrm{C} \cdot \mathrm{min}^{-1}$. The thermal stability of plasticized PVC films was carried out using a Q50 thermogravimetric analyzer (TGA) of TA instruments ${ }^{\circledR}$. The experiments consisted in registering the weight loss of the sample under air flow (60 $\mathrm{mL} \cdot \mathrm{min}^{-1}$ ) in function of temperature ranging from 25 up to $500{ }^{\circ} \mathrm{C}$ with a heating rate of $10^{\circ} \mathrm{C} \cdot \mathrm{min}^{-1}$ and isothermal at $200{ }^{\circ} \mathrm{C}$ for 2 hours. Plasticized PVC film hardness was 
evaluated with a Shore A durometer (HBA 100-0) from Sauter. Elongation at break and Young modulus of the films were measured with an Instron 3366L5885 tensile tester according to ISO 527-3:1995 standards. Films were cut into 8 strips of $1.2 * 15 \mathrm{~cm}$ and mounted between tensile grips with an initial grip spacing of $10 \mathrm{~cm}$. The cross-head speed was $200 \mathrm{~mm} \cdot \mathrm{s}^{-1}$ and the elongation at break was expressed as a percentage of the original length.

\section{Plasticizer Eco-toxicity}

Toxicity and eco-toxicity tests were performed by EUROFINS Expertises Environnementales $N^{\circ}$ ZAQ220170076-04.

Toxicity measurements with algae Pseudokirchneriella subcapitata (cultivation of tests organisms and preparation of the solid dilution) were performed in fresh water in accordance with OCDE Guideline 201 (OECD, 1984). This medium was composed of deionised water $(800 \mathrm{ml})$ and a mix of solution $1(10 \mathrm{~mL}), 2(1 \mathrm{~mL}), 3(1 \mathrm{~mL})$ and $4(1 \mathrm{~mL})$ where the chemical ingredients are listed in Table 1SI. Pseudokirchneriella subcapitata strain is CCAP278/2 and comes from SAMS Research Service Ltd, Scotland. An algal culture in the exponential growth phase was exposed to a screening of different concentrations from $1 \mathrm{mg} / \mathrm{L}$ to $100 \mathrm{mg} / \mathrm{L}$ of the tested substance under controlled conditions, during $72 \mathrm{~h}$ to determine the critic concentration of the tested product which inhibits the algal growth until $75 \%$ maximum. Another test was conducted at this concentration to determine the $\mathrm{ECr}_{\mathrm{x}}$ at $72 \mathrm{~h}$ (concentration in $\mathrm{mg} / \mathrm{L}$ of the tested product for which the algal growth is reduced of $\mathrm{x} \%$ compared to the control solution). All these tests were performed at $21-25^{\circ} \mathrm{C}$ with a daily light (7500 lux) and algae were observed under a microscope Olympus BH-2.

The acute toxicity tests of Daphnia magna were conducted following OECD guideline 202 (OECD 202, 2004). Daphnia magna strain is D. magna straus clone 5 and comes from EBSE 
Metz France. Test solution were prepared in reconstituted freshwater where the chemical ingredients are listed in Table 2SI. The hatching of ephippia of D.magna was performed at 20 ${ }^{\circ} \mathrm{C}$ for $72 \mathrm{~h}$ under continuous illumination (6000 lux). The neonates were fed with Spirulina powder. Plasticizer was placed in test plates containing test wells ( 5 neonates per well). After incubation in the dark at $20{ }^{\circ} \mathrm{C}+/-2{ }^{\circ} \mathrm{C}$ for $24 \mathrm{~h}$, the immobility was determined every $24 \mathrm{~h}$ for 48 and compared to the control. The $\mathrm{pH}$ was measured at the beginning and at the end of the test. The test was considered valid if the number of immobile organisms in the controls did not exceed $10 \%$ after the $48 \mathrm{~h}$ incubation. For this test, the reference toxicant was potassium dichromate $\left(\mathrm{K}_{2} \mathrm{Cr}_{2} \mathrm{O}_{7}\right)$.

\section{Estrogenic and androgenic activity characterization}

YES-YAS tests were performed by EUROFINS Expertises Environnementales $\mathrm{N}^{\circ}$ ZAQ220170076-04.

The XenoScreen YES/YAS assay kits were obtained from Xenometrix AG (Allschwill, Switzerland). A special care was taken to avoid the contact of solvents and reagents with plastic materials, thus preventing possible interaction between plasticizers while performing the assay. In order to minimize the risk of secondary contamination, glass materials were used in place of plastic materials anywhere it was possible and sterilized. In order to better dissolve samples, prepared solutions were laced $30 \mathrm{~min}$ in an ultrasonic bath. The standard solution's endocrine potency was immediately evaluated after the preparation. Each time, after testing, plasticizer's solutions were refrigerated at $4{ }^{\circ} \mathrm{C}$.

Test YES-YAS uses yeast cells Saccharamoyces cerevisiae stably modified by introducing a gene encoding the hormone receptors hER $\alpha$ (YES) or hAR (YAS). Cells were incubated with serially diluted substances and positive control (17- $\beta$ estradiol for YES assay, and $5 \alpha-$ dihydrotestosterone for YAS) for $48 \mathrm{~h}$ at $30{ }^{\circ} \mathrm{C}+/-2{ }^{\circ} \mathrm{C}$ in the presence of a substrate for $\beta$ - 
galactosidase synthesis. Androgens or estrogens, and compound with activity similar to the sex hormones can form complexes with modified yeasts receptors. Thus, formed complexes interact with DNA fragments located on the plasmids containing the $\beta$-galactosidase gene (lacZ). the activation of the hormone receptors (hER $\alpha$ or hAR) by the blinding of an endocrine active substance leads to the expression of $\beta$-galactosidase. The lac $Z$ gene expression exclusively depends on concentration of hormones and endocrine-active substances. Expression of b-galactosidase is directly related to the presence of activating (agonist) or inhibiting (antagonist) activity of the tested compound and drives the conversion of a yellow substrate chlorophenol red-b-D-galactopyranoside (CPRG) into chlorophenol red. The color change and growth of yeast are quantitatively measured using a microplate spectrophotometer at, respectively, 570 and $690 \mathrm{~nm}$ wavelength light. The results are evaluated in terms of agonistic and antagonistic effect of estrogen and androgen. The test also evaluates the cytotoxic effect of the test compound by testing the optical density of each well $(\lambda=690 \mathrm{~nm})$. Assessment of an estrogen-androgen activity was performed for the plasticizer CEC18:1Ep at eight different dilution levels. Each assay was repeated four times.

Dose-response curves were fitted using the sigmoid dose-response function in GraphPad Prism software. EC50 and NOEC values were calculated for those compounds which exhibited a complete dose-response curves. A tested compound was considered to have agonistic endocrine activity if the induction was at least $10 \%$ of the difference between the maximum E2 or DHT response and solvent control in agonist assay. A sample dilution that inhibited negative control activity (medium with agonist) by at least 50\% was considered to have antagonistic endocrine activity in antagonist assay. 


\section{Results and discussion}

\section{Synthesis of epoxidized cardanol fatty esters}

Based on our previous review on the design of the chemical structure of plasticizers [31], a carbonyl group was incorporated into the cardanol structure by using a Steglish esterification with fatty carboxylic acid (Figure 2, step A). This functionalization increases the dipolar forces improving the compatibility between the plasticizer and PVC. Otherwise, the addition of dangling long chains enhances the mobility of the polymer chains. A second step consisting in bulk epoxidation of the unsaturations of cardanol and fatty chains with $\mathrm{H}_{2} \mathrm{O}_{2}$ is performed to enhance miscibility, plasticizing and thermal stability properties (Figure 2, step B). Note that acetylated cardanol derivatives, CE2 and CE2Ep, bearing short alkyl chain, have already been described in literature in different PVC matrices showing good plasticizing effect with PVC.[29]

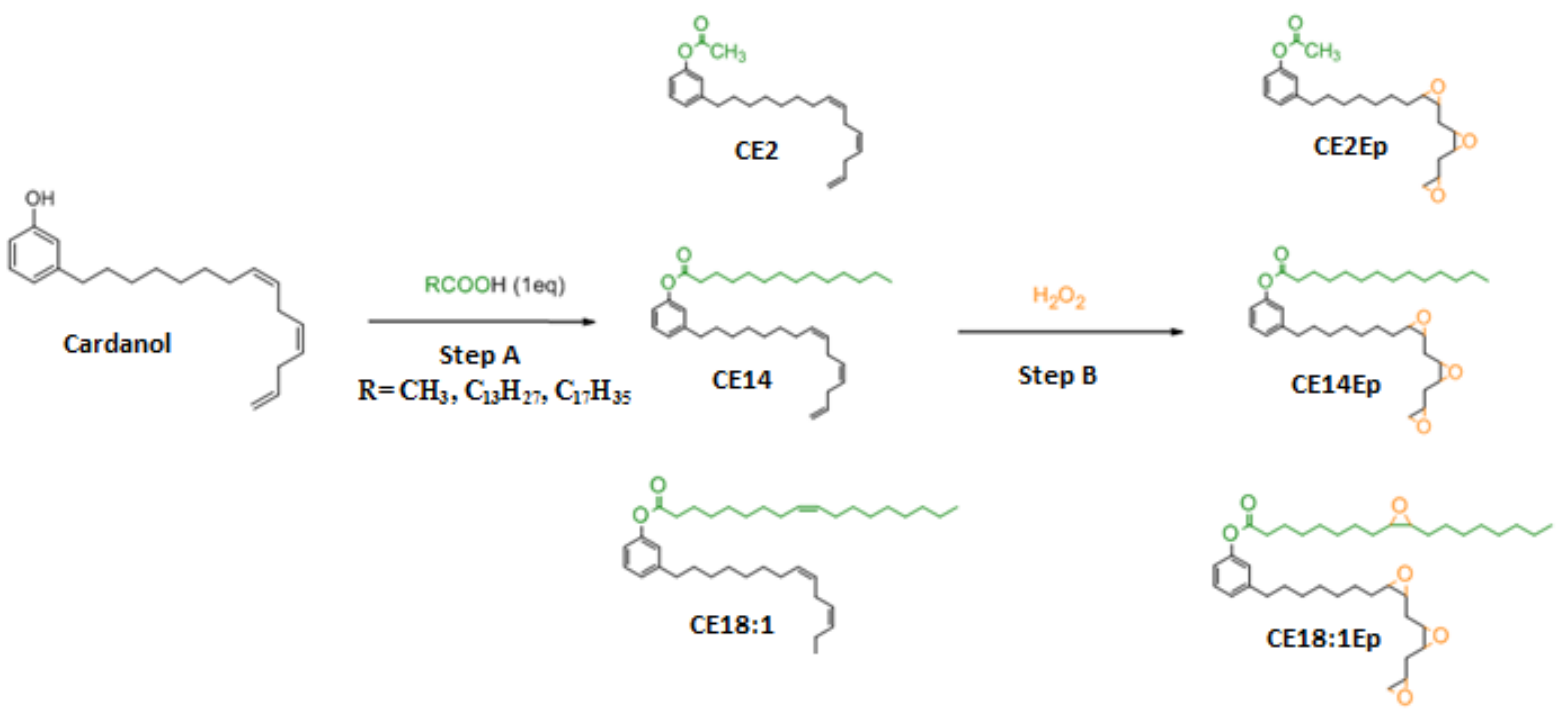

Figure 2. Synthesis of the non epoxidized (CEx) and epoxidized (CExEp) plasticizers 
The Steglish esterification of the cardanol phenol group was performed with acetic acid (C2), myrisitic acid (C14) and oleic acid (C18:1) reaching 86\% yield. The chemical structure of the cardanol esters CEx were confirmed by ${ }^{1} \mathrm{H}$ NMR and FTIR spectroscopies. As illustrated in Figure 3, the characteristic ${ }^{1} \mathrm{H}$ NMR signals of phenolic protons (a, b, c and d) shift from 6.64, 6.75 and $7.1 \mathrm{ppm}$ to $6.85,7.00$ and $7.22 \mathrm{ppm}$. The double bond signals between 4.95 and 5.88 ppm are not modified by the esterification. Additional aliphatic proton signals corresponding to the grafted alkyl chain are observed at $2.54 \mathrm{ppm}(\mathrm{Hf})$ and at $1.61 \mathrm{ppm}(\mathrm{Hm})$. Moreover, FTIR spectra shows that $\mathrm{O}-\mathrm{H}$ phenol signal disappeared at $3333 \mathrm{~cm}^{-1}$ whereas a $\mathrm{C}=\mathrm{O}$ peak of the carbonyl ester group appeared (Figure 4).

Next, the epoxidation of the double bonds was monitored by NMR spectroscopy regarding the presence of epoxidized groups at 2.86-2.94, 2.94-3.01 and 3.04-3.20 ppm attributed to j, k, 1 protons respectively (Figure 3). Nevertheless, residual ethylenic protons were detected since the epoxidation conversion was close to $85 \%$ and was calculated using i, h, g signals between 4.95 and $5.88 \mathrm{ppm}$. The differentiation of terminal $(\mathrm{Hi}$ and $\mathrm{Hg}$ ) and ethylenic protons along the alkyl and fatty chains demonstrated the lower epoxidation conversion of terminal unsaturations (55\%) than internal ones (94\%) as previously reported by Jaillet and al. [32] 


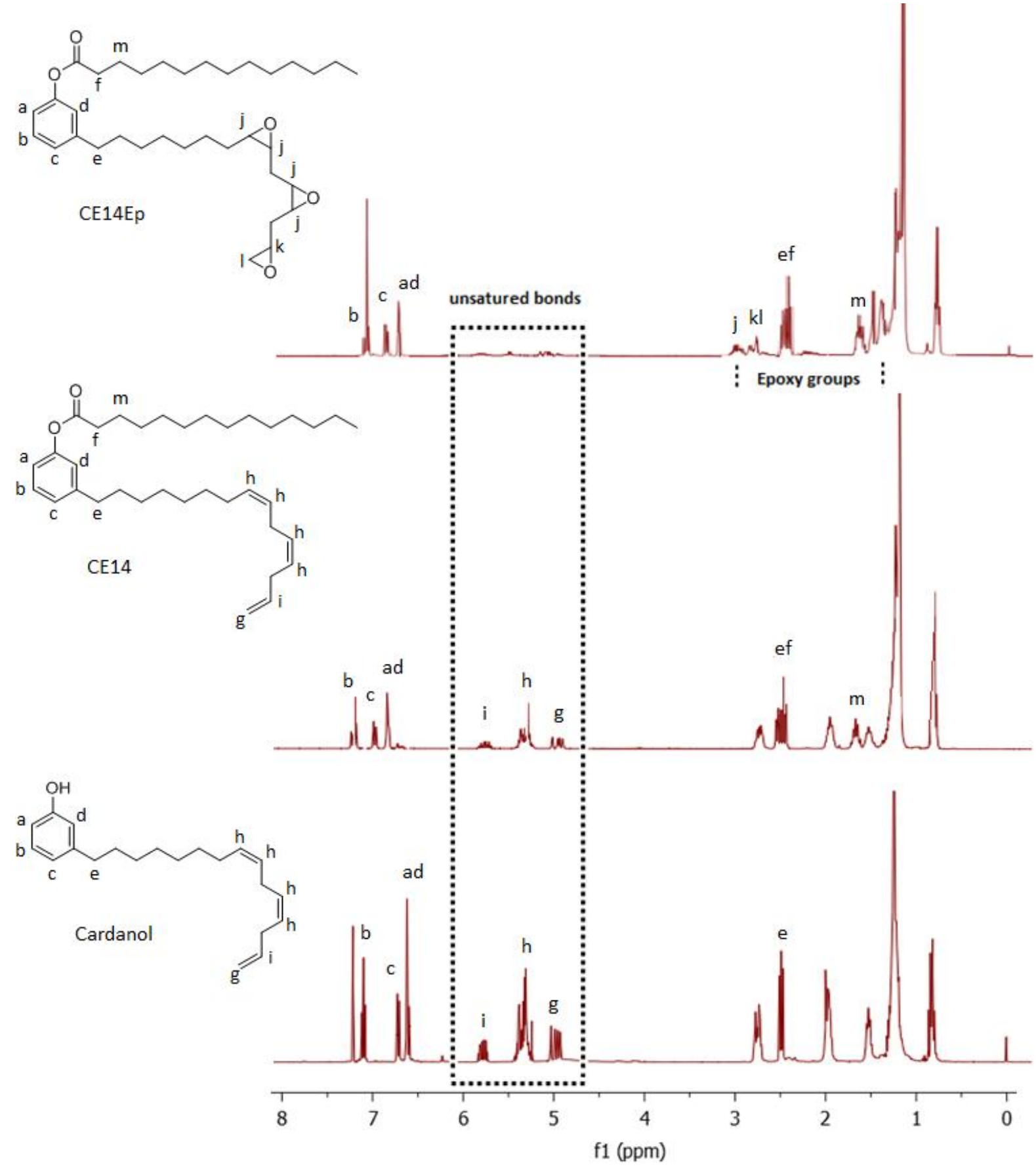

Figure 3. ${ }^{1} \mathrm{H}$ NMR spectra of cardanol, $\mathrm{CaCC14}$ and CaeC14Ep in $\mathrm{CDCl}_{3}$ 


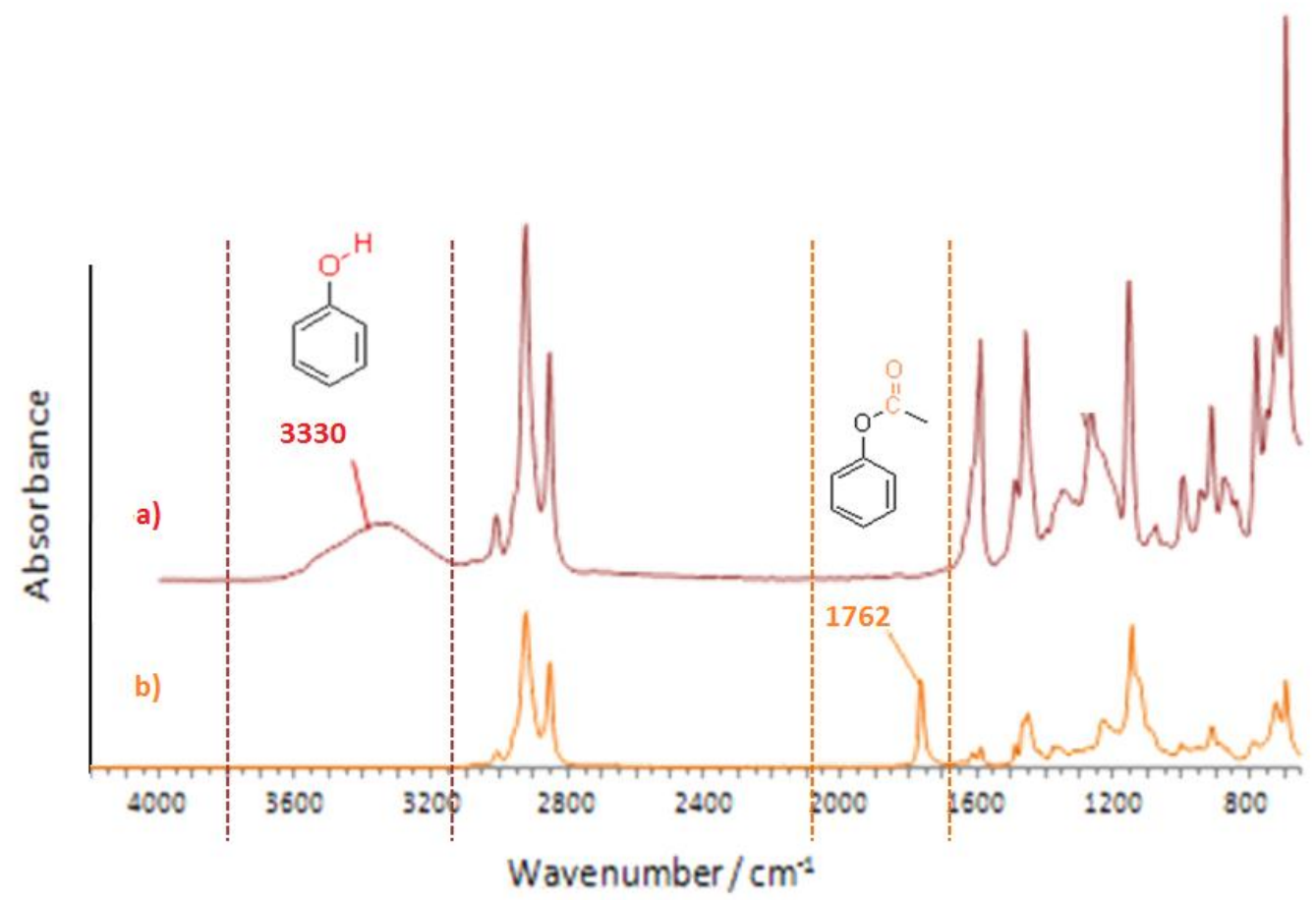

Figure 4. FTIR spectra of a) cardanol and b) CE18:1

\section{Study of plasticized PVC}

With the aim of establishing structure-plasticizing properties relationship, the presence of ester, fatty chains and epoxy groups has been thoroughly studied. Ester are the most widespread functional group in PVC plasticizers because they allow specific interactions with the polymer (hydrogen bonds, electrostatic, or van der Waals interactions) acting as cohesive blocks. [17] Previous studies [30] reported the positive influence of epoxy groups on thermal stability of PVC or other chlorine-containing polymers, acting as scavenger for $\mathrm{HCl}$ and labile chlorine atoms. Furthermore, epoxidation can causes a reduction of the leaching of the plasticizer, due to a decrease of the diffusion coefficient of the plasticizer. We also note the dangling fatty and cardanol chains to create free volume between polymer chains and increase its mobility and finally soften the resulting materials. 
Two generations of cardanol based plasticizer were reported. The first generation, cardanol ester plasticizers, CEx (Figure 2, step A), were immiscible with PVC. Hence, they were mixed with DINP $(50 / 50 \mathrm{w} / \mathrm{w})$ and tested as secondary plasticizers, in order to reduce the quantity of DINP in PVC formulation. The second generation, epoxidized cardanol esters, CExEp, (Figure 2, step B) were directly miscible in PVC. Therefore, they were tested as primary plasticizers. The plasticized PVC films were elaborated after $10 \mathrm{~min}$ at $190{ }^{\circ} \mathrm{C}$ of a plastisol resulting from the plasticizer-PVC blend (PVC/plasticizer: 60/40 w/w) without any solvent (THF...) as often described. To evaluate the efficiency of the plasticizers, they were compared to DINP, a commercial phthalate plasticizer frequently used with PVC. Glass transition temperature $(\mathrm{Tg})$ is commonly accepted as effective index of the plasticizing efficiency knowing that a low $\mathrm{Tg}$ means a good compatibility between the plasticizer and PVC. $[11,33] \mathrm{T} \alpha$, which is related to $\mathrm{Tg}$, can be measured by dynamic mechanical analyses (DMA). The temperature corresponding to loss tangent peak was taken as T $\alpha$ as usually performed. The values gathered in Table 1 are lower than that of PVC T $\alpha\left(80^{\circ} \mathrm{C}\right)$, confirming a plasticizing effect even if CEx plasticizers with fatty chains stay around $44-46{ }^{\circ} \mathrm{C}$ (CE14/DINP and CE18:1/DINP) revealing a poor compatibility of the additive with the PVC matrix despite presence of 50\% of DINP. On the other hand, CE2 as secondary plasticizer and epoxidized cardanol-ester plasticizers as primary ones lead to T $\alpha$ values close to that of PVCDINP, around room temperature, showing a good compatibility with PVC. Regarding these values, CExEp plasticizers could be considered as interesting alternatives to DINP, and more generally, phthalates, for soft PVC.

\section{Thermal properties of the PVC films}

Thermal properties of CEx-PVC And CExEp-PVC films (PVC/plasticizer: 60/40 w/w) were determined by thermogravimetric analysis (TGA) under air flow as shown in Figure 5. All the 
TGA curves split in three degradation steps. The first weight loss from around 150 to $350{ }^{\circ} \mathrm{C}$ corresponds to the cleavage of hydrogen chloride $(\mathrm{HCl})$ inducing a polyene formation by dehydrochlorination. Then this degradation is followed by a plateau ranging from 350 to 440 ${ }^{\circ} \mathrm{C}$. Whatever the plasticizer, the last degradation step starts around $440{ }^{\circ} \mathrm{C}$ and can be explained by complex mechanisms involving cross-linking of $\mathrm{C}=\mathrm{C}$ bond and formation of char. [34] During the first step of degradation, 5\% weight loss of PVC plasticized with CExDINP: CE14-DINP $\left(247^{\circ} \mathrm{C}\right)$ and CE18:1-DINP $\left(243{ }^{\circ} \mathrm{C}\right)$ occurred at similar temperatures than PVC-DINP $\left(242^{\circ} \mathrm{C}\right)$ while that of PVC-CE2 and PVC-CE2-DINP happen earlier, at 222 and $231{ }^{\circ} \mathrm{C}$, respectively. Hence, plasticized PVC with epoxidized cardanol CExEp, exhibits a better thermal stability than with DINP, with respective 5\% weight loss at 255, 277 and 283 ${ }^{\circ} \mathrm{C}$ for CE2Ep, CE14Ep and CE181Ep, which demonstrates the importance of epoxy rings for thermal stability of soft PVC.

Moreover, the weight loss is related to the presence of DINP. For PVC-DINP, only $22.6 \%$ of the starting material remains after the first decomposition related to PVC-[CEx-DINP] where $30 \%$ of the material remains. The more significant result concerns PVC-CExEp without DINP where around $40 \%$ of material are still present, meaning a better thermal stability of the materials plasticized without DINP. The differences observed in the first step of degradation could be explained by the fact that cardanol is well-known as good thermal stabilizer. [29, 35] In our case, the epoxide groups trap $\mathrm{HCl}$ produced during the degradation of $\mathrm{PVC}$, thanks to the interaction between epoxide groups and labile $\mathrm{Cl}$ atoms of the PVC. [36] The epoxy groups impact the thermal stability as it can be seen on the isothermal at $200{ }^{\circ} \mathrm{C}$ (Figure 6). Related to DINP, CEC18:1Ep film loss $16 \%$ of the weight after 128 min whereas only 30 min were required for DINP to reach the same weight loss amount. Moreover, CE181:1Ep film is more stable than PVC alone, showing that this plasticizer improved the thermal stability of the polymer itself too. Epoxidized Cardanol based esters have shown better thermal properties 
than DINP and drastically limit the dehydrochlorination step. To conclude CE18:1Ep has shown the best thermal stability, even better than CE2Ep already described in the literature. [29]
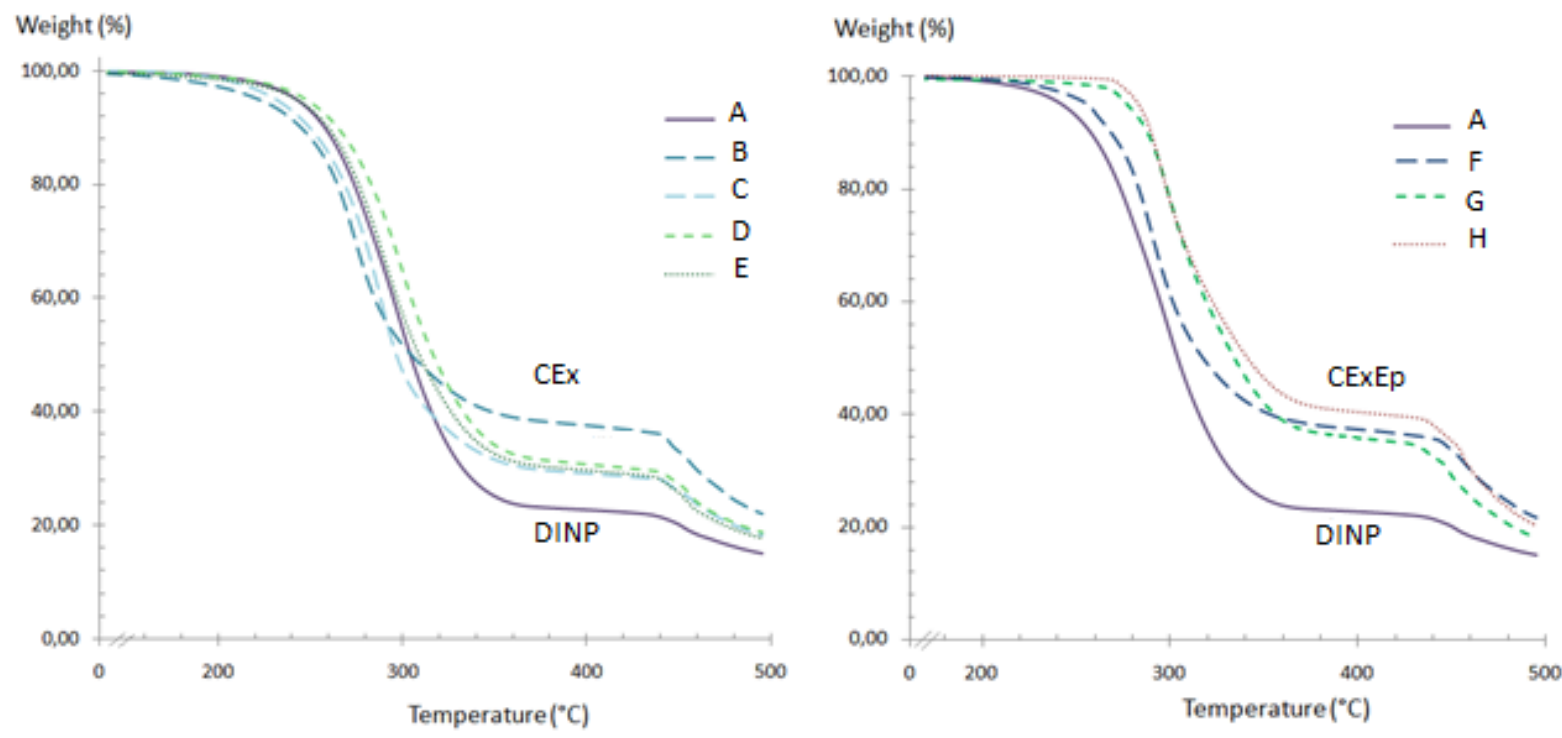

Figure 5. TGA curves of plasticized PVC films 


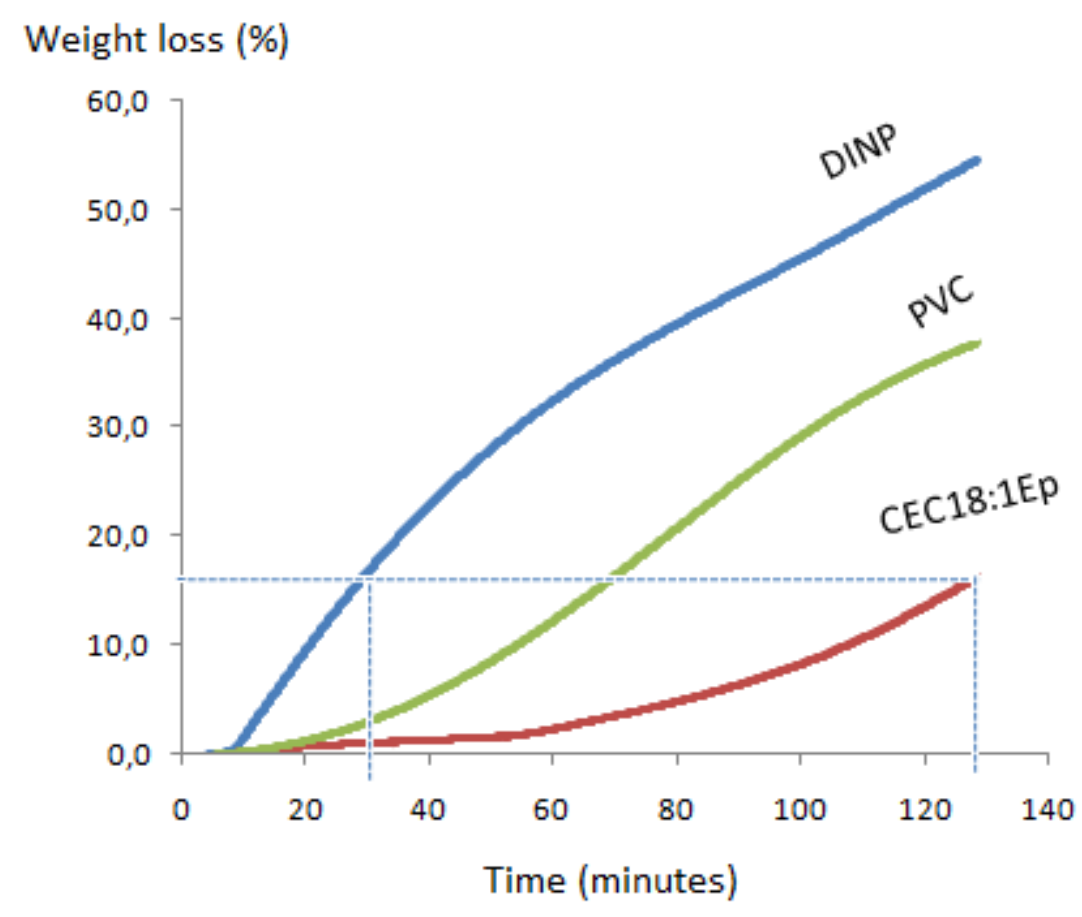

Figure 6. TGA isothermal at $200{ }^{\circ} \mathrm{C}$ of PVC and plasticized PVC films using DINP and CEC18:1Ep

\section{Mechanical Properties}

Mechanical characterizations were also performed on plasticized PVC films since a poor compatibility polymer-additive results in a low elongation at break. The results of the tensile measurements reported in Figure 7 show two types of curves. PVC plasticized with the mix of CEx/DINP lead to more brittle films with a decrease of the elongation at break (B) (220$250 \%$ ) in comparison to DINP (325\%), and a higher young modulus (E) with 21.6 and 30.8 MPa for CE14-DINP and CaeC18:1-DINP, respectively. Only the blend between CE2 and DINP (340\% and 7.6 MPa) is close to DINP alone (8.8 MPa). PVC plasticized with CE2 alone exhibits lower E (5.5 MPa) but breaks earlier (290\%). By contrast, all the films plasticized by CExEp are more flexible than PVC-DINP film, with a Young modulus of 4-6.7 MPa compared to 8.8 MPa. Moreover, PVC-CExEp films exhibit similar or higher elongation at break (320-341\%) than PVC-DINP (325\%), which indicates that the flexibility is improved 
and confirms the good compatibility of these additives with PVC. Without DINP, CExEp plasticized PVC films show same or better tensile properties than the reference with DINP, showing that epoxidation have a real impact of the flexibility and elongation of the plasticized PVC films. This behavior can be explained by the interaction between the oxirane and the PVC.

Furthermore, the shore A hardness was measured for soft PVC samples. The results reported in Table 3 show that when Young modulus increases, hardness increases as well. Substitution of DINP by CExEp has only a little influence on the hardness of the material, which is in agreement with their close moduli previously discussed.

In this study, CEC18:1Ep seems to be the best candidate for substitute phthalate in soft PVC formulation. To prove the safety of this plasticizer, its eco-toxicity and its endocrinal disruptor impacts were investigated and compared to DINP.

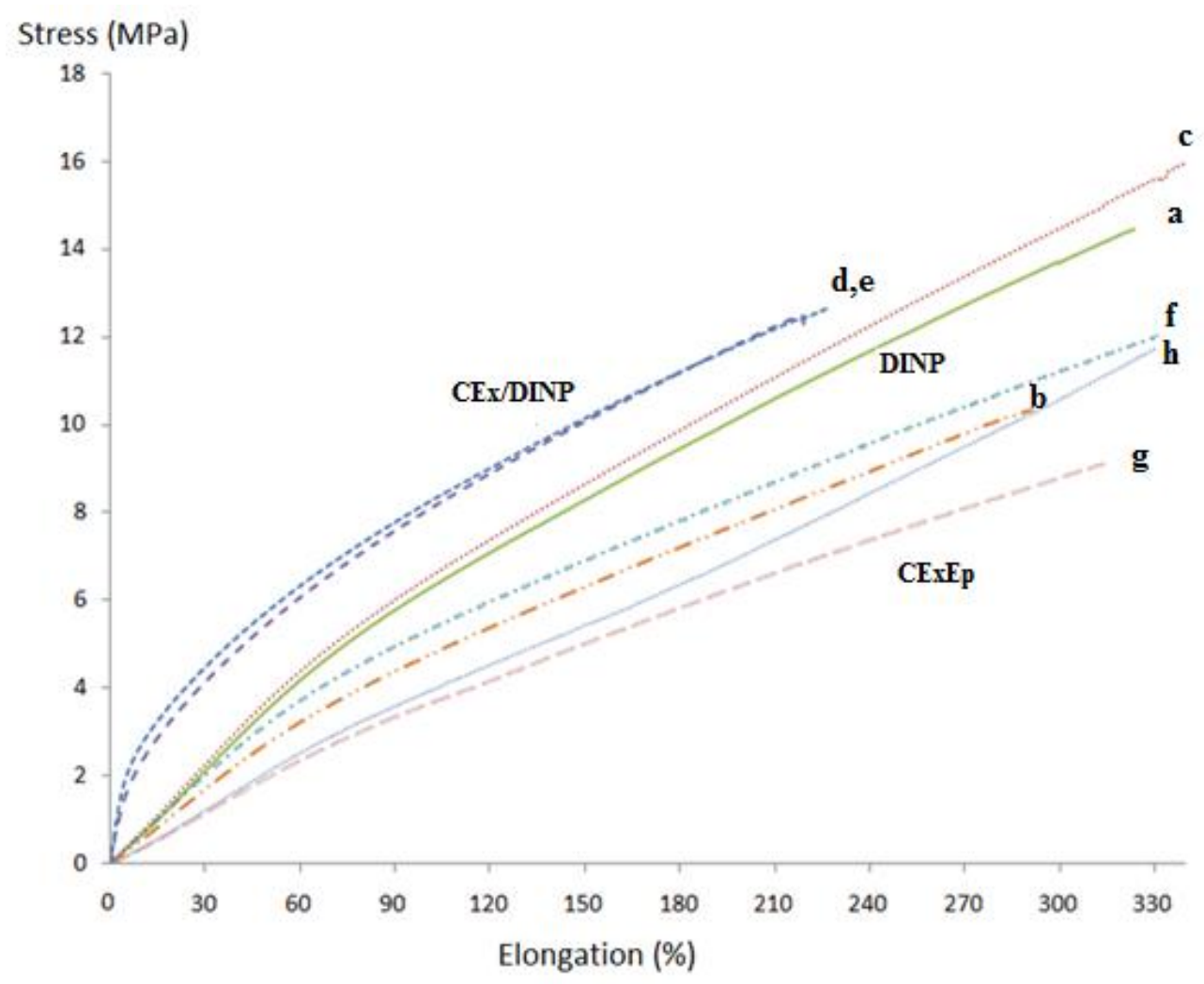

Figure 7. Stress-strain curves of plasticized PVC 
Table 3: TGA, Tensile, DMA and hardness values of plasticized PVC films

\begin{tabular}{|c|c|c|c|c|c|c|c|}
\hline $\begin{array}{c}\text { Formulation } \\
\text { PVC 60\%-Plasticizer 40\% }\end{array}$ & Name & $\begin{array}{c}\text { B } \\
(\%)\end{array}$ & $\begin{array}{c}E \\
(\mathrm{MPa})\end{array}$ & Shore A & $\begin{array}{l}\mathrm{T}_{\alpha} \\
\left({ }^{\circ} \mathrm{C}\right)\end{array}$ & $\begin{array}{l}\mathrm{T}_{5 \%} \\
\left({ }^{\circ} \mathrm{C}\right)\end{array}$ & $\begin{array}{c}W_{400^{\circ} \mathrm{C}} \\
(\%)\end{array}$ \\
\hline PVC (100\%) & PVC & - & - & - & 80 & 262 & 35.8 \\
\hline PVC-DINP & A & 325 & 8.8 & 35 & 12 & 242 & 22.6 \\
\hline PVC-CE2 & B & 290 & 5.5 & 30 & - & 222 & 37.6 \\
\hline $\begin{array}{c}\text { PVC- [CE2-DINP] } \\
(50 / 50)\end{array}$ & C & 340 & 7.6 & 43 & 18 & 231 & 29.2 \\
\hline $\begin{array}{c}\text { PVC- [CE14-DINP] } \\
(50 / 50)\end{array}$ & $\mathrm{D}$ & 220 & 21.6 & 47 & 44 & 247 & 30.7 \\
\hline $\begin{array}{c}\text { PVC- [CE18:1-DINP] } \\
(50 / 50)\end{array}$ & $E$ & 250 & 30.8 & 60 & 46 & 243 & 29.7 \\
\hline PVC-CE2Ep & $\mathrm{F}$ & 330 & 4.2 & 39 & 12 & 255 & 37.3 \\
\hline PVC-CE14Ep & G & 341 & 6.7 & 45 & 20 & 277 & 35.8 \\
\hline PVC-CE18:1Ep & $\mathrm{H}$ & 320 & 4 & 40 & 20 & 283 & 40.2 \\
\hline
\end{tabular}




\section{Eco-toxicity tests of CEC18:1Ep plasticizer}

Eco-toxicity tests of CEC18:1Ep were performed in synthetic freshwater media at neutral $\mathrm{pH}$ on algae Pseudokirchneriella subcapitata and Daphnia magna in comparison to $\mathrm{K}_{2} \mathrm{Cr}_{2} \mathrm{O}_{7}$ (as reference), and DINP (MSDS Diisononyl phthalates, version 2.0, 07-25-2013, Brenntag according to Regulation 1907/2006/CE) (Figure 8). CEC18:1Ep reveals both no toxicity on Daphnia after $48 \mathrm{~h}$ and no toxicity on algae after $72 \mathrm{~h}$ showing that the $\mathrm{EC}_{50}$ value exceeds 100 $\mathrm{mg} / \mathrm{L}$ in both cases. By contrast, for DINP, the $\mathrm{EC}_{50}$ values with Daphnia and algae were estimated to 74 and 88 , respectively. The lower eco-toxicity than DINP and the safety of CEC18:1Ep plasticizer were unambiguously demonstrated.

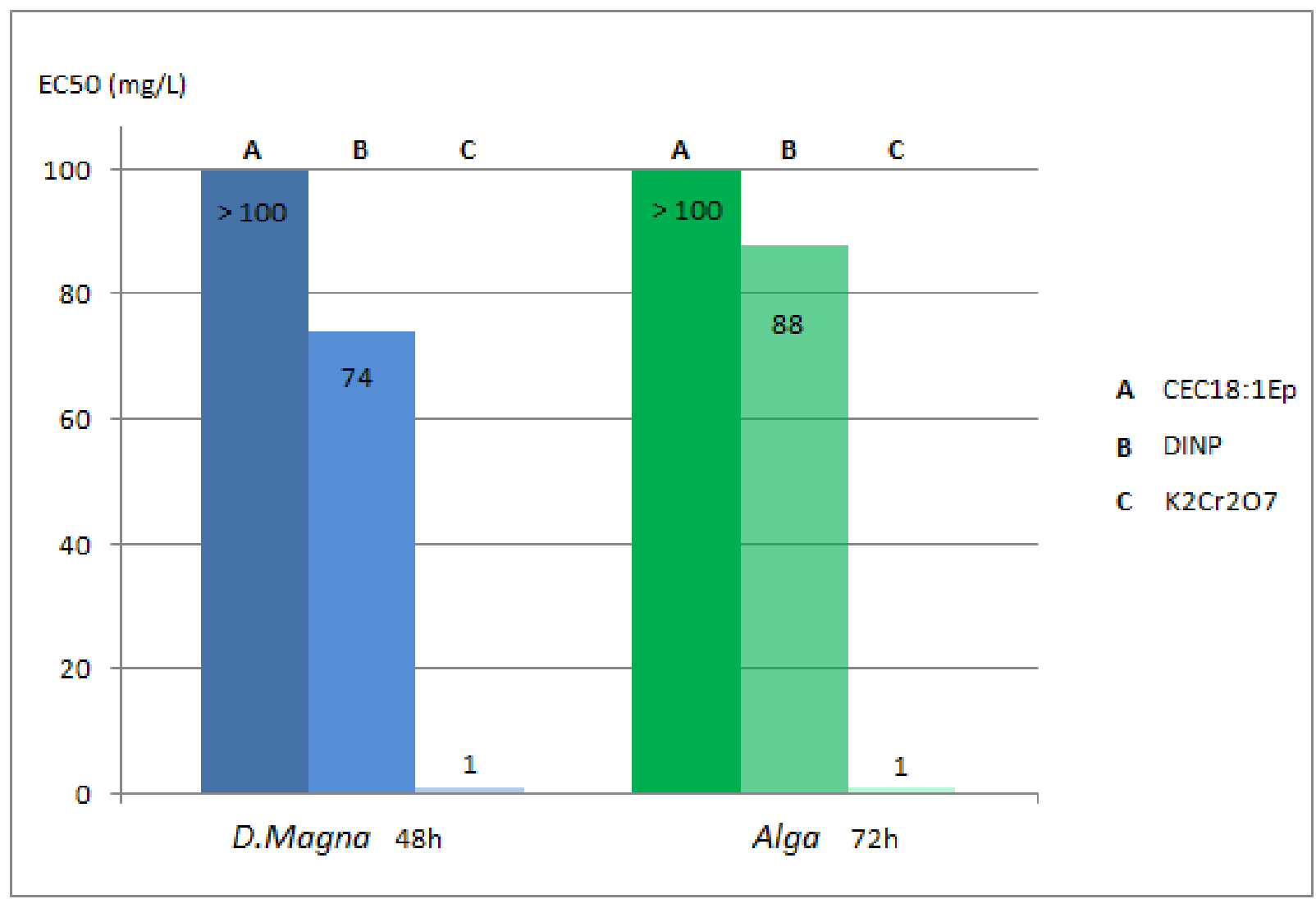

Figure 8. $\mathrm{EC}_{50}$ to Daphnia magna after $48 \mathrm{~h}$ and to Alga after 72h of CEC18:1Ep, DINP and $\mathrm{K}_{2} \mathrm{Cr}_{2} \mathrm{O}_{7}$ 


\section{Determination of estrogenic and androgenic activities of CEC18:1Ep plasticizer}

As already described by Czernych and al [37], the assessment of an endocrine potential done by using in vitro methods has obvious limitations. It's not possible to evaluate the endocrine potency of plasticizer metabolites. Nevertheless, the YES/YAS test helps to reduce the area of uncertainty about the endocrine action of plasticizer. In this part, CE18:1Ep plasticizer was compared to the phthalates studied by Czernych including diisononyl phthalate (DINP), diethyl phthalate (DEP), dibutyl phthalate (DBP), butyl benzyl phthalate (BBzP) and di(2ethylhexyl)phthalate (DEHP).

The tested plasticizer shows no agonistic properties in relation to female (YES) or male (YAS) hormones. The effective concentration values $\left(\mathrm{EC}_{50}\right)$ can't to be calculated and 100 $\mathrm{mg} / \mathrm{L}$ wasn't enough to have a response. DINP has also no significant agonistic properties but more than CEC18:1. For estrogenic tests, DINP has a 5 order of magnitude higher of $\mathrm{EC}_{50}$ related to $17 \beta$-estradiol and for androgenic tests, DINP has 2 order higher of $\mathrm{EC}_{50}$ values related to $5 \alpha$-dihydrotestosteron (Table 2). Moreover, Czernych and al [37] previously shown that the phthalate having the less activity on agonistic endocrine effect (female or male) was DEP with respectively an estrogenic $\mathrm{EC}_{50}$ of $17.10 \mathrm{M}$ and an androgenic EC50 of $35.30 \mathrm{M}$, far below CEC18:1Ep values.

The CEC18:1Ep plasticizer also shows no antagonist properties in relation to female hormone (YES antagonist) by contrast to DINP revealing a strong antagonist effect ( 2 order lower than 4-hydroxytamoksifen). Finally, CEC18:1Ep has a little androgenic antagonistic effect (YAS antagonist) even if no assessment of concentration can be done. Consequently, a $\mathrm{EC}_{50}$ value of $140 \mathrm{M}$ was extrapolated - 8 order higher than Flutamid and 10 order higher than DINP which, has a strong antagonist effect on male hormones. The other phthalates of the study, show lower impact on antagonistic properties on female or male hormones. To conclude, in 
addition to good plasticizing properties, CEC18:1Ep doesn't reveal any significant agonistic or antagonistic properties on female or male hormones.

Table 2: Endocrine results and comparison with DINP

\begin{tabular}{ccc}
\hline & & EC/IC \\
\hline Yes agonist & $(\mathbf{M})$ \\
& $17 \beta$-estradiol & $5.08 \mathrm{E}-05$ \\
& DINP & 0.069 \\
& CEC18:1EP & No activity \\
\hline Yas agonist & $5 \alpha$-dihydrotestosteron & $5.15 \mathrm{E}-03$ \\
& DINP & 0.11 \\
Yes & CEC18:1EP & No activity \\
antagonist & 4-hydroxytamoksifen & $1.74 \mathrm{E}-06$ \\
& DINP & $6.53 \mathrm{E}-08$ \\
Yas & CEC18:1EP & No activity \\
\hline antagonist & Flutamid & $8.52 \mathrm{E}-06$ \\
& DINP & $6.79 \mathrm{E}-08$ \\
& CEC18:1EP & 140 (extrapolated) \\
\hline
\end{tabular}




\section{Conclusion}

We investigated the synthesis of bio-based and no toxic phthalate substituent plasticizers for PVC. Two generations of plasticizers were elaborated: non epoxidized (G1) and epoxidized (G2) cardanol plasticizers. The better thermal stability and plasticizing properties (softer PVC films) of the G2-PVC films can be explained by the synergy between the epoxy groups (scavenger during the PVC degradation) and the cardanol aromatic ring (thermal stabilizing). The grafting of long fatty chains (carrier of epoxy groups) seems to be the origin of the good results related to previous study with acetyl group on cardanol. Thus, the molecular design of plasticizers bearing epoxy groups, cardanol aromatic ring and fatty chains reaches efficient primary plasticizers, better than phthalates including DINP already used. Additionally, with the very low eco-toxicity (daphnia and algae) and repro-toxicity without significant effect on agonistic or antagonistic properties for both, female and male hormones, CEC18:1Ep plasticizer is a good fully bio-based candidate as phthalate substituent plasticizer for PVC films.

\section{Acknowledgments}

This work was funded by the SAS PIVERT, within the frame of the French Institute for the Energy Transition (Institut pour la Transition Energétique (ITE) P.I.V.E.R.T. (www.institutpivert.com) selected as an Investment for the Future ("Investissements d'Avenir"). This work was supported, as part of the Investments for the Future, by the French Government under the reference ANR-001-01. The cardanol used in this study was freely given by Cardolite. 


\section{References}

1. Persico, P., et al., Processability and mechanical properties of commercial PVC plastisols containing low-environmental-impact plasticizers. Journal of Vinyl and Additive Technology, 2009. 15(3): p. 139-146.

2. Navarro, R., et al., Phthalate Plasticizers Covalently Bound to PVC: Plasticization with Suppressed Migration. Macromolecules, 2010. 43(5): p. 2377-2381.

3. Chen, J., et al., A novel biobased plasticizer of epoxidized cardanol glycidyl ether: synthesis and application in soft poly(vinyl chloride) films. RSC Advances, 2015. 5(69): p. 56171-56180.

4. $\quad \mathrm{Bi}, \mathrm{X}$. , et al., Plasticizer Contamination in Edible Vegetable Oil in a U.S. Retail Market. Journal of Agricultural and Food Chemistry, 2013. 61(39): p. 9502-9509.

5. Fenollar, O., et al., Optimization of the curing conditions of PVC plastisols based on the use of an epoxidized fatty acid ester plasticizer. European Polymer Journal, 2009. 45(9): p. 26742684.

6. Jia, P., et al., Development of a vegetable oil based plasticizer for preparing flame retardant poly(vinyl chloride) materials. RSC Advances, 2015. 5(93): p. 76392-76400.

7. Zheng, X.-G., et al., Dehydrochlorination of PVC Materials at High Temperature. Energy \& Fuels, 2003. 17(4): p. 896-900.

8. Becker, K., et al., DEHP metabolites in urine of children and DEHP in house dust. International Journal of Hygiene and Environmental Health, 2004. 207(5): p. 409-417.

9. Choi, J. and S.Y. Kwak, Hyperbranched poly(epsilon-caprolactone) as a nonmigrating alternative plasticizer for phthalates in flexible PVC. Environmental Science \& Technology, 2007. 41(10): p. 3763-3768.

10. Hill, S.S., B.R. Shaw, and A.H.B. Wu, The clinical effects of plasticizers, antioxidants, and other contaminants in medical polyvinylchloride tubing during respiratory and non-respiratory exposure. Clinica Chimica Acta, 2001. 304(1-2): p. 1-8.

11. Jia, P.Y., et al., Effect of chlorinated phosphate ester based on castor oil on thermal degradation of poly (vinyl chloride) blends and its flame retardant mechanism as secondary plasticizer. RSC Advances, 2015. 5(51): p. 41169-41178.

12. Koch, H.M., H.M. Bolt, and J. Angerer, Di(2-ethylhexyl)phthalate (DEHP) metabolites in human urine and serum after a single oral dose of deuterium-labelled DEHP. Archives of Toxicology, 2004. 78(3): p. 123-130.

13. Mekonnen, T., et al., Progress in bio-based plastics and plasticizing modifications. Journal of Materials Chemistry A, 2013. 1(43): p. 13379-13398.

14. Sampson, J. and D. de Korte, DEHP-plasticised PVC: relevance to blood services. Transfusion Medicine, 2011. 21(2): p. 73-83.

15. Vieira, M.G.A., et al., Synthesis and Application of Natural Polymeric Plasticizer Obtained Through Polyesterification of Rice Fatty Acid. Materials Research-Ibero-American Journal of Materials, 2014. 17(2): p. 386-391.

16. Xie, Z.H., et al., Effects of Bio-based Plasticizers on Mechanical and Thermal Properties of PVC/Wood Flour Composites. Bioresources, 2014. 9(4): p. 7389-7402.

17. Bocque, M., et al., Petro-Based and Bio-Based Plasticizers: Chemical Structures to Plasticizing Properties. Journal of Polymer Science Part a-Polymer Chemistry, 2016. 54(1): p. 11-33.

18. da Silva, M.A., et al., Polyvinylchloride (PVC) and natural rubber films plasticized with a natural polymeric plasticizer obtained through polyesterification of rice fatty acid. Polymer Testing, 2011. 30(5): p. 478-484.

19. Yang, P., et al., Novel environmentally sustainable cardanol-based plasticizer covalently bound to PVC via click chemistry: synthesis and properties. RSC Advances, 2015. 5(22): p. 16980-16985.

20. Voirin, C., et al., Functionalization of cardanol: towards biobased polymers and additives. Polymer Chemistry, 2014. 5(9): p. 3142-3162. 
21. Facanha, M.A.R., et al., Evaluation of antioxidant properties of a phosphorated cardanol compound on mineral oils (NH10 and NH20). Fuel, 2007. 86(15): p. 2416-2421.

22. Rao, B.S. and A. Palanisamy, Synthesis of bio based low temperature curable liquid epoxy, benzoxazine monomer system from cardanol: Thermal and viscoelastic properties. European Polymer Journal, 2013. 49(8): p. 2365-2376.

23. Yadav, R. and D. Srivastava, Studies on the process variables of the condensation reaction of cardanol and formaldehyde by response surface methodology. European Polymer Journal, 2009. 45(3): p. 946-952.

24. Sultania, M., J.S.P. Rai, and D. Srivastava, Modeling and simulation of curing kinetics for the cardanol-based vinyl ester resin by means of non-isothermal DSC measurements. Materials Chemistry and Physics, 2012. 132(1): p. 180-186.

25. Barreto, A.C.H., et al., Properties of sisal fibers treated by alkali solution and their application into cardanol-based biocomposites. Composites Part a-Applied Science and Manufacturing, 2011. 42(5): p. 492-500.

26. Chen, Q.H., H.Y. Xue, and J.H. Lin, Preparation of Polypropylene-graft-Cardanol by Reactive Extrusion and Its Composite Material with Bamboo Powder. Journal of Applied Polymer Science, 2010. 115(2): p. 1160-1167.

27. Sandrino, B., et al., Amphiphilic porphyrin-cardanol derivatives in Langmuir and LangmuirBlodgett films applied for sensing. Colloids and Surfaces a-Physicochemical and Engineering Aspects, 2013. 425: p. 68-75.

28. Tanaka, S., H. Honzawa, and M. Iji, Development of cardanol-bonded cellulose thermoplastics: High productivity achieved by using isocyanate-modified cardanol. Journal of Applied Polymer Science, 2013. 130(3): p. 1578-1587.

29. Greco, A., et al., Plasticizer for poly(vinyl chloride) from cardanol as a renewable resource material. Polymer Degradation and Stability, 2010. 95(11): p. 2169-2174.

30. Greco, A., F. Ferrari, and A. Maffezzoli, Effect of the epoxidation yield of a cardanol derivative on the plasticization and durability of soft PVC. Polymer Degradation and Stability, 2016. 134: p. 220-226.

31. Bocqué, M., et al., Petro-based and bio-based plasticizers: Chemical structures to plasticizing properties. Journal of Polymer Science Part A: Polymer Chemistry, 2015. 54(1): p. 11-33.

32. Jaillet, F., et al., A chemical platform approach on cardanol oil: from the synthesis of building blocks to polymer synthesis. OCL, 2016. 23(5): p. D511.

33. Jia, P.Y., et al., Synthesis and characterization of glyceryl monooleate-based polyester. Korean Journal of Chemical Engineering, 2015. 32(3): p. 547-551.

34. Chen, J., et al., Synthesis and application of a natural plasticizer based on cardanol for poly(vinyl chloride). Journal of Applied Polymer Science, 2015. 132(35).

35. Menon, A.R.R., C.K.S. Pillai, and G.B. Nando, Modification of natural rubber with phosphatic plasticizers: a comparison of phosphorylated cashew nut shell liquid prepolymer with 2-ethyl hexyl diphenyl phosphate. European Polymer Journal, 1998. 34(7): p. 923-929.

36. Thames, S.F., et al., Surfactants and Fatty Acids: Plant Oils, in Biopolymers from Renewable Resources, D.L. Kaplan, Editor 1998, Springer Berlin Heidelberg: Berlin, Heidelberg. p. 249280.

37. Czernych, R., et al., Characterization of estrogenic and androgenic activity of phthalates by the XenoScreen YES/YAS in vitro assay. Environmental Toxicology and Pharmacology, 2017. 53(Supplement C): p. 95-104. 